\title{
Direito, violência e religião em Habacuque: a partir da leitura do Leviatã hobbesiano
}

\author{
Right, Violence and Religion in Habacuque: from Leviatã \\ Hobbesian Reading
}

Ashbell Simonton Rédua ${ }^{1}$

Resum o: Analisa e discute neste artigo a relação da violência bíblica no profeta Habacuque, a partir dos conceitos desenvolvidos por Thomas Hobbes na obra Leviatã, segundo o qual será abordado questões sobre a linguagem da violência em Habacuque tomando por princípio a linguagem antropomórfica desenvolvido no contex to bíblico que procura dar forma humana a Deus a fim de que o homem possa entender os atos e as ações de Deus na história da humanidade. A falta de entendimento da linguagem antropomórfica, nos humanos, definiremos Deus como um ser violento, vingativo e cruel, contudo não é assim que percebe ao aplicar no contexto das Escrituras Sagradas o princípio filosófico da linguagem na definição da violência no contexto bíblico. Na primeira parte do texto é bem definido o que é linguagem antropomórfica e como podemos subtrair desta interpretação a correta compreensão da violência nas Escrituras Sagradas. Na segunda parte do artigo, analisa-se a questão da violência na perspectiva hobbesiana no emprego da poder e do direito (justiça), destaca-se que a violência segundo Hobbes é um instrumento do medo, portanto e originária do poder e da justiça. Como princípio da reflexão das ciências da religião,

Artigo recebido em: 27 mar 2018 Aprovado em: 03 ago. 2018

${ }^{1}$ Ashbell S., Redua é mestrando profissional em Ciência da Religião, curso oferecido pela Faculdade Unidade de Vitória, com ingresso em 2018.1; 
na terceira parte tratamos do Deus humano em Habacuque, delimitando as reações de emoções e sentimentos, alteração gradual da compreensão transcendental de "Deus além de nós", que prevaleceu foi a concepção de imanente de "Deus por nós", para a percepção de "Deus em nós", o resultado desta alteração é que Deus é rebaix ado ao nível humano, de modo que as pessoas possam interagir mais prontamente com Ele, sendo aplicado os princípios do Estado do Leviatã. Oendurecimento do poder estatal, leis mais severas, a justiça mais rígida são elementos capaz de refrear a violência e instalar uma sociedade de paz social.

Palav ras-chave: Habacuque, profeta, linguagem, religião, violência.

Abstract: It analyzes and discusses in this article the relation of biblical violence in the prophet Habakkuk, based on the concepts developed by Thomas Hobbes in Leviathan, according to which questions will be approached about the language of violence in Habakkuk taking as principle the anthropomorphic language developed in the biblical context that seeks to give human form to God so that man may understand the acts and actions of God in the history of mankind. The lack of understanding of anthropomorphic language in humans will define God as a violent, vengeful and cruel being, but this is not the way he perceives in the context of the Scriptures the philosophical principle of language in the definition of violence in the biblical context. In the first part of the text it is well defined what anthropomorphic language is and how we can subtract from this interpretation the correct understanding of violence in the Holy Scriptures. In the second part of the article, we analyze the question of violence in the Hobbesian perspective in the use of power and law (justice), it is pointed out that the violence according to Hobbes is an instrument of fear, therefore and originating from power and justice. As a principle of reflection of the sciences of religion, in the third part we deal with the human God in Habakkuk, delimiting the reactions of emotions and feelings, gradual change of transcendental understanding of "God beyond us," which prevailed was the immanent conception of "God for us, "for the perception of" God in us, "the result of this change is that God is lowered to the human level, so that people can interact more readily with Him, applying the principles of the Leviathan State. The hardening of state power, stricter laws, more rigid justice are elements capable of curbing violence and establishing a society of social peace.

Key words: Habakkuk, prophet, language, religion, violence

\section{Introdução}

Pode a religião ser a causa da violência? São as pessoas violentas por natureza? Pode alguém utilizar o nome de Deus causar violência? O Deus registrado nas páginas das Escrituras 
Sagradas é um Deus violento? Pode alguém utilizar o nome de Deus para matar? Acreditamos que o tema é pertinente nos dias de hoje, uma vez que estamos inseridos em um contexto de intolerância religiosa e violência física. Teria a religião mecanismos para legitimar a violência? Afinal o que é violência e como se processa sua linguagem? A partir de uma análise superficial, é fácil afirmar que o aumento da violência estaria relacionado com a religião e que esta fomentaria a ideia de que outras religiões, outros deuses, o diferente, não teriam o mesmo direito de coexistir e por isso devem ser segregados e/ou eliminados por meio de atitudes nem sempre pacíficas. De outro lado, não podemos negar que a violência permeia a história da humanidade desde tempos longínquos, apresentase multifacetada e com diferentes matizes e muitas vezes as religiões promoveram a violência.

A violência tem muitas fases e frentes de estudo, neste caso foi preciso delimitar a violência apenas nos escritos do profeta Habacuque partindo da leitura do Leviatã de Thomas Hobbes. Neste aspecto faz-se necessário entender como a violência pode ser legitimada pela religião e, ao mesmo tempo, como o estudo do fenômeno religioso pode contribuir para melhor entender as relações socioculturais e políticas nos dias atuais. Como as crenças e as práticas religiosas de um determinado grupo étnico poderiam construir e legitimar práticas violentas? Quais as relações entre a religião, a violência e a globalização? E, sobretudo, há uma relação entre a religião e a violência ou a violência é própria da natureza humana? Para responder a essas questões, cada pesquisador se ocupou com uma das formas em que a relação entre religião e violência pode ser vislumbrada na sociedade atual. Mas poderia a teoria política hobbesiana servir base para entendermos melhor o processo da aparente violência registrada nas Bíblia?

Neste texto procuro analisar teoricamente o livro do profeta Habacuque, a fim de identificar a questão da violência relacionada com o direito e a religião a partir da linguagem do Leviatã de Thomas Hobbes. No primeiro tópico descrevi a linguagem da violência em Habacuque, que é uma linguagem antropomórfica da violência. No segundo item, identificando o Estado Leviatã, que deve agir na defesa de todos, não 
permitindo o estado de violência, pela imposição do poder manifestado pela obediência e pelo medo. No tópico terceiro tratamos do Deus humano em Habacuque, delimitando as reações de emoções e sentimentos, alteração gradual da compreensão transcendental de "Deus além de nós", que prevaleceu foi a concepção de imanente de "Deus por nós", para a percepção de "Deus em nós", o resultado desta alteração é que Deus é rebaixado ao nível humano, de modo que as pessoas possam interagir mais prontamente com Ele.

\section{A linguagem antropomórfica da violência em Habacuque}

A partir de uma análise superficial de Habacuque não é difícil de afirmar que a violência gera violência, e que o aumento da violência está intimamente relacionado com a religião. Contudo podemos também afirmar que a violência não somente está relacionada com a religião, mas com qualquer grupo humano, e isto é perceptível na história da humanidade, seja como referencia as Escrituras Sagradas ou as históricas com diferentes visões de outros povos com outros processos religiosos, mas que geralmente se manifestam sob a ótica da violência. Assim antes de entendermos o significado de violência em Habacuque, precisamos entender o que é violência e como a linguagem da violência se manifesta na cultura humana. Tanto a religião como a violência "possuem uma complexidade muito grande" 2 , há muitas controvérsias no campo da fenomenologia da religião, principalmente na legitimidade da violência no contexto da religião. "Esses e outros fatores dificultam a produção de resultados difíceis de organizar de forma coerente e satisfatória"3, portanto a pesquisa requer uma metodologia baseada na interpelação "conceitual" 4 .

A religião tem o poder de direcionamento de todos os atos e ações do indivíduo, "mantendo um conjunto de práticas e deveres que dão significado a existência das pessoas,

2 OLIVEIRA, Irene Dias, apud. Religião, violência e suas interfaces. São Paulo: Paulinas, 2012.

3 OLIVEIRA, p. 8

4 OLIVEIRA, p. 8 
constitui a expressão dinâmica das camadas sociais e representa uma maneira de afirma-se em sua própria cultura" 5 . Segundo Hobbes religião é o medo dos poderes invisíveis, inventados pelo espírito ou imaginados a partir dos relatos publicamente permitidos, no caso em estudo as Escrituras Sagradas. ${ }^{6}$ Locke propõe uma religião racional7, capaz de estar sob o controle da razão humana. Contudo para Rubens Alves, a religião é um fato social ${ }^{8}$. A religião para os teóricos da filosofia "enquanto forma de comportamento cujas regras se afastam das que regulam a vida diária, assenta numa dicotomia introduzida no mundo das referências humanas, que se traduz num duplo nível de realidade - o sagrado e o profano."9 Diferentemente das proposições anteriores a ciência da religião preocupa-se não em definir o que é religião, mas investigar o fenômeno religioso e a sua influência na pessoa humana, a partir das ciências, isto é, na utilização d vários métodos das ciências religiosas aglutinando-as num único trabalho.

A relação da fenomenologia com os estudos sociais relacionados à religião se inscreve no movimento teórico e metodológico das ciências sociais que diz respeito à compreensão da sociedade, especialmente, na crítica antropológica da distinção entre sujeito e objeto. Além do materialismo histórico protagonizado por Karl Marx, existem duas outras grandes tradições teóricas das Ciências Sociais das Religiões muito usadas até meados de 1970 . Uma representada pelo francês E. Durkheim e outra pelo alemão M. Weber. Ambos reconhecem o potencial da religião enquanto força social, mas se o primeiro tendeu à descrição das partes que compõem a religião - os mitos e os ritos - e os tomou para pensar, "lá na ponta", a ordenação da sociedade, o segundo direcionou sua pesquisa para a compreensão da

5 OLIVEIRA, p. 9, cita cita Berger (BERGER, Peter Ludwig. O dossel sagrado; elementos para uma teoria sociológica da religião. São Paulo: Paulinas, 2004.) p. 9

${ }^{6}$ HOBBES, Thomas. O Leviatã. São Paulo: Victor Civita Editor, 1974.

7 LOCKE, John. Carta acerca da tolerância. São Paulo: Abril Cultural, pág. 03-39

8 ALVES, Rubens. Oque é religião. São Paulo: Brasiliense, 1984.

9 JORDÃO, Francisco Vieira. A religião sob o ponto de vista filosófico. Revista Filosófica de Coimbra - n. ${ }^{\circ} 4$ - vol . 2 (1993 ) pp. 295-311 
religião como aquilo que produz ética e conforma os comportamentos. ${ }^{10}$

Partindo deste princípio, os profetas eram homens que exerciam o ofício a margem da religião oficial dos judeus. A sua profecia não tinha a influência dos sacerdotes e nem dos reis, e, por esta razão o exercício da profecia era uma atividade alternativa. A religião hebreus era o monoteísmo, campo de atuação dos profetas bíblicos, os quais tem o compromisso de conhecer a "realidade religiosa como dimensão essencialmente humana" 11 o que significa perceber a religião "além de suas estruturas básicas, também as formas que essa realidade foi tomando ao longo do tempo."12 A religião dos Israelitas na época dos profetas faz parte da própria estruturação do poder político, havendo reconhecimento tanto do poder religioso como do poder político. "Nesse processo, criaram-se estruturas de diferenciação e exclusão, tanto externa como internamente."

Nesse contexto, ao mesmo tempo em que se estruturou em Israel um governo monárquico e uma religião oficial, a espiritualidade dos profetas rememorava os tempos do período tribal, em que prevalecia uma oposição à realidade de governo dos povos vizinhos, que era a monarquia ${ }^{13}$.

O sistema governamental centralizador dos hebreus era a teocracia, ainda que no período de Habacuque já havia realizado a transição para a monarquia, mesmo assim, a organização política era um governante humano direcionado por Deus. Deus governava através do monarca. Portanto é possível justificar este modelo diante das outras nações, contudo é na religião oficial dos hebreus que autentica a

10 RODRIGUES, Elisa. As Ciências Sociais da Religião como Ciências da Interpretação. Estudos de Religião, v. 28, n. 1, 186-203, jan.-jun. 2014 11 SANTOS, Tiago Bueno. A estruturação da religião monoteístano antigo Israel. UNITAU: XIV Encontro Latino Americano de Iniciação Científica e X Encontro Latino Americano de Pós-Graduação - Universidade do V ale do Paraíba. Disponível

em http://www.inicepg.univap.br/cd/INIC 2011/anais/arquivos/0266 0173 o4.pdf, acesso em 14.02.18. p.1

12 SANTOS, 2011. p.1

13 SANTOS, 2011,p.2 
centralização e o domínio do monarca que neste contexto das ações do governo surge a figura dos profetas, a margem da religião oficial, cuja mensagem era caracterizado pela denuncia as injustiças cometidas pelos controladores do poder político-sacerdotal. Pode-se perceber exatamente este viés na denuncia do profeta Habacuque contra a exploração do pobre e justiça distorcida, tudo isto autenticado pela poder políticoreligioso. Para Habacuque a violência, a corrupção deve ser vencida pelo lado divino, pelo Senhor da Guerra, e é por esta razão que o profeta clama a Deus por libertação contra a violência.

Tratar da violência nos escritos do profeta Habacuque, requer primeiro a conceituação de religião e o caminho a percorrer. O caminho definido é a matriz da religião sob a investigação da fenomenologia vivenciado pelo profeta na sua época e na sua história, que parte da visão do monoteísmo. A segunda interpelação conceitual se refere ao que se entende por violência na linguagem bíblica, que se define como uma linguagem antropomórfica, que é atribuir a Deus uma linguagem humana, atribuindo sentimentos, pensamentos, emoções, ações e comportamentos próprios do homem. Esta linguagem humaniza Deus a fim de ser entendido os seus atos na história da humanidade.

\section{A violência como força de justiça e poder}

Segundo Hobbes, o Estado é o Leviatã, que deve agir na defesa de todos, não permitindo o estado de violência, principalmente a violência contra a vida. O poder estatal deve garantir as relações pactuadas e impor pelo obediência e pelo medo. A violência que se funda no direito pode ser entendida como violência conservadora, preservadora dos princípios constituídos pelos Estado. Violência e força constitui direito que precisa ser aplicado na construção de um sistema de justiça. A palavra "violência" é uma palavra latina "violentus" e significa força. Portanto qualquer "instrumento de violência, se opõe ou, ao menos de imediato, não coaduna com paz. Mas, contrariando nossos sentimentos mais compassivos, podemos 
atinar a razão de sua existência como ferramenta necessária para estabelecer, restaurar e manter a Paz." 14

Beltrami ${ }^{15}$ ao citar Jacques Derrida demonstra o imperativo da união entre a violência como força com a justiça, "justiça sem força é contradita e força sem justiça é autoritária" 16 , portanto a justiça exige o emprego da força para que realmente possa ser aplicada no contexto humano. A violência gerada pela força é necessária para que a justiça seja aplicada de forma justa. "A necessidade da força está pois implicada no justo da justiça." 17 Assim pois de igual forma a violência é legitimada pelo poder absoluta da autoridade estatal, neste aspecto devemos entender que existe uma violência contra a própria violência. Violência instituída, portando é uma violência legal e a violência não constituída é uma violência ilegal, conforme evoca o profeta Habacuque: opressão e justiça distorcida. No contexto de Habacuque "à essência da violência divina, manifesta o poder e a justiça de Deus.

"A violência divina é a mais justa, a mais efetiva, a mais histórica, a mais revolucionária, a mais decidível e a mais decisória. Mas, como tal, ela não se presta a nenhuma determinacão humana, a nenhum conhecimento ou "certeza" decidível de nossa parte. Nunca a conhecemos nela mesma, "como tal", mas somente em seus "efeitos". Seus efeitos são "incomparáveis”. Eles não se prestam a nenhuma generalidade conceitual, a nenhum juízo determinante. Só há certeza (Gewissheit) ou conhecimento determinante no domínio da violência mítica, isto é, do direito, isto é, da indecibilidade histórica." 18

14 FÉLIX, Luciene. A violência da justiça. Disponível em http://www.esdc.com.br/CSF/artigo 2009 07 Violencia da Justica.htm , capturado em 23.02.18

15 BELTRAMI, Fábio. Força de lei: o fundamento místico da autoridade. Conjectura: Filos. Educ., Caxias do Sul, v. 18, n. 3, p. 196-199, set./dez. 2013, p. 199 16 BELTRAMI, 2013, P.199.

17 DERRIDA, Jacques. Força de lei. São Paulo: M. Fontes, 2010. P.19 18 DERRIDA, 2010. P. 129-130 
Os teóricos alemães utilizaram o termo Gewalt para violência, força, poder, e pode ser empregado para definir o poder como autoridade, como por exemplo o poder judiciário, o poder do soberano, o poder patriarcal, poder espiritual e poder do Estado. "Freud propõe substituir o par direito (Recht) e poder (Macht), que Einstein havia empregado, por direito (Recht) e violência (Gewalt), e tenta mostrar como esses dois termos que hoje parecem se opor têm uma origem comum, "um se desenvolveu a partir do outro". ${ }^{19}$ O Leviatã do profeta Habacuque deve ser estabelecido porque este sociedade é uma sociedade sem lei, cuja justiça é distorcida, portanto ao invocar a paz dívida, Deus se manifesta contra a violência suscitando um povo, os Caldeus, homens mais violentos, Portanto não há dúvida que a violência é o estado originário da paz, difundido pela força e pelo poder. Assim "durante o tempo em que os homens vivem sem um poder comum capaz de os manter a todos em respeito, eles se encontram naquela condição a que se chama guerra; e uma guerra que é de todos os homens contra todos os homens." 20

Notemos que em Habacuque, que a marca da violência é definida como a exclusão decorrente da iniquidade e da opressão social. O ímpio, diz Habacuque, cerca o justo, e a justiça se manifesta distorcida. Se a justiça é o reconhecimento do direito do próximo, a injustiça é a negação, é o bloqueio, a obstrução. Nesta perspectiva o discurso mental consiste em construir um sinal linguístico que é o discurso verbal que nomeie as ações de Deus no contexto da violência manifestada na sociedade hebraica na época do profeta Habacuque. E como se pode perceber a linguagem verbal conclui-se de que a violência se combate com a violência. As palavras de Hobbes ganham outra conotação diante desta realidade, "o homem é o lobo do homem".

“A linguagem é a representação dos desejos do homem, ou seja, a representação de suas paixões. Dada uma paixão, o pensamento põe-se à procura

19 VANIER, Alain. Direito e violência.Ágora v. VII n. 1 jan/jun 2004 129141.

20 HOBBES, Thomas. Leviatã ou matéria: forma e poder de um estado eclesiástico e civil. Tradução de João Paulo Monteiro e Maria Beatriz Nizza da Silva. $2^{\text {a }}$ ed. Os pensadores. São Paulo: Abril Cultural, 197 9. P. 75-76 
dos objetos que a configurem - discurso mental; ou então, dada a definição de uma paixão, o pensamento conclui a respeito das condições formais de sua satisfação: discurso verbal.” ${ }^{21}$

Segundo Hobbes, os homens usam a violência para promover o lucro, depois para ter segurança e por fim para ter reputação. ${ }^{22}$ "Se o medo da morte violenta foi o propulsor da criação do Estado-Leviatã, a vida é o bem maior do homem.”, ${ }^{23}$ está associado a consciência daquilo que configura como mais vantajoso e que pode produzir um viver em paz. O que é mais vantajoso segundo Hobbes é viver sob a tutela de um Estado Soberano. "O reino de Deus se ganha pela violência." 24 Aqui a violência é um sinônimo de esforço, e neste esforço os indivíduos vivem juntos não em razão da religião, da linguagem, da raça, cor, sexo, visão de mundo, ideologias, mas por estarem subordinados as mesmas leis, regras, direitos, justiça deveres e obrigações, que são comuns a todos que vivem dentro de um Estado Soberano.

\section{Deus humano de Habacuque: sentimentos e emoções.}

Fora da relação entre proteção do Estado e obediência ao Estado, cuja relação baseia-se no medo, desta feita o medo da punição ${ }^{25}$, o homem não teria qualquer camaradagem ou responsabilidade para com seus pares. Segundo Hobbes, o Estado pode ser estabelecido de duas maneiras: por instituição, quando os homens concordam em submeterem-se a um homem ou a uma assembleia ou por aquisição, quando o domínio se impõe pela força. Em ambos os casos, o poder se impõe pelo medo. "A questão da violência e do mal - e, por

\footnotetext{
${ }^{21}$ MATOS, Ismar Dias. Uma descrição do elemento humano em Thomas Hobbes. São Paulo: Annablume, 2007. P. 62

22 HOBBES, 1974. P.46

23 MATOS, Ismar Dias. Hobbes e a violência. Sapere aude - Belo Horizonte, v. 7 - n. 12, p. 509-514, Jan./Jun. 2016 - ISSN: 217 7-6342.

P.511

24 HOBBES, 1974 , P. 52

25 HOBBES, 1974 , P. 48
} 
contraste, também da não violência - está, portanto, no centro da reflexão hodierna sobre a religião e o fenômeno religioso.” 26

A religião dos hebreus é rica em símbolos e ritos, que se corporificam nas Escrituras Sagradas institucionalizado o Estado. "Diante do sagrado, a relação vem carregada de respeito, de mistério, de silêncio, de ritos, de temor, de medo." 27 . Este é o drama de Habacuque se mostra perplexo, pois a violência se alastra e Deus não se importa, não providência nenhuma solução. Deus se apresenta como apático, indiferente e silencioso, distante, inerte, incapaz de resolver toda aquela situação. É justamente nesses momentos de angústia e aflição que o profeta se sente esquecido, abandonado por Deus. Abandono é também uma espécie de violência, por isto quando o profeta se sente abandonado pela inércia de Deus, sente aquilo que podemos chamar de "abandono da alma". O abandono não vem de Deus, mas da inquietação interna do ser humano. Diante desse quadro sombrio, Habacuque questiona a justiça e a presença de Deus: "onde está o Deus de justiça”? Onde Ele se escondeu?:

Advertência do profeta Habacuque. Até quando, Senhor, clamarei por socorro, sem que tu ouças? Até quando gritarei a ti: "Violência! " sem que tragas salvação? Por que me fazes ver a injustiça, e contemplar a maldade? A destruição e a violência estão diante de mim; há luta e conflito por todo lado. Por isso a lei se enfraquece e a justiça nunca prevalece. Os ímpios prejudicam os justos, e assim a justiça é pervertida. 28

A grande dificuldade de Habacuque é "entender os desígnios de um Deus crido como soberano no mundo tal qual

26 BINGEMER, Maria Clara. Violência e religião: questão prioritária. Disponível em Este www.teologiahoy.com, acesso em 03.02.18.

27 MANGONI, José Antonio. Violência e idolatria no cristianismo. Porto Alegre: PUC, dissertação de mestrado, Disponível em http://meriva.pucrs.br/dspace/bitstream/10923/5295/1/000269461Texto\%2BCompleto-0.pdf, capturado em 24.02.18 28 FILHO, Élcio Verçosa. A Providência dos Profetas: uma leitura da doutrina da ação divina na bíblia hebraica a partir de Abraham Joshua Heschel. Cadernos Teologia Prática: UNISINOS, ano XI, número 83, 2014. 
ele é, cheio de violência e opressão." ${ }^{29}$. Contudo apesar do medo proporcionado pela invasão dos Caldeus, o profeta jamais concordaria com Hobbes e sua teoria contratualista. Parece que, pela teoria hobbesiana, Habacuque deveria ter se preocupado não em orar a Deus, reclamando e requerendo as mudanças necessárias para o seu povo, proporcionando um Estado legal na busca de transformar a sociedade, ainda que pelo medo, e não invocado a justiça de Deus para a solução dos problemas morais vividos por sua gente. 30 "Se a instituição do Leviatã é aquilo que traz ao mundo a paz e a justiça, o que poderia fazer de Hobbes, o precursor da mentalidade burguesa e da conseguinte corrida imperialista que viriam a desafiar a estabilidade das leis e a própria existência das comunidades políticas?”. ${ }^{31}$

No decorrer da história, Habacuque percebe que houve uma alteração gradual da compreensão transcendental de "Deus além de nós" para a concepção de imanente de "Deus por nós", para a percepção de "Deus em nós", o resultado desta alteração é que Deus é rebaixado ao nível humano, de modo que as pessoas possam interagir mais prontamente com Ele. Habacuque tenta humanizar Deus (antropomorfismo), atribuindo as características humanas tais como humildade, compaixão, misericórdia, bondade. A importância desse humanizar representa o poder de estabelecer e assegurar a igualdade social face às tendências opressoras de fora e às tendências não igualitárias de dentro. Assim como Israel proíbe outros sistemas dentro de sua organização social, assim também Deus é zeloso e proíbe outros deuses. A consciência de povo escolhido é um reflexo da consciência de uma sociedade de iguais. $3^{2}$

29 SAY ÃO. Luiz. O problema do mal no Antigo Testamento: o caso de Habacuque. São Paulo: Hagnos. 2012

3o MENDES, Juscelino Vieira. O Positivismo Jurídico de Hans Kelsen e o profeta-filósofo Habacuque: determinantes na aplicação da Justiça. Revista de direito: Kroton Educacional, v. 9, n. 11, 2006

${ }^{31}$ SANTOS, Rodrigo Ponce. Hobbes e a filosofia do poder: os 'princípios' antipolíticos do leviatã na leitura de Hannah Arendt. KRITERION, Belo Horizonte, $n^{o} 136, A b r . / 2017, p .211$

32 KIPP, Nelson. A sociedade e a religião do Israel libertado. São Leopoldo: Est. Revista Estudo Teológicos. ISSN o101-3130 (impresso) ISSN 2237 6461

(eletrônico).

Texto disponível

em 
Encontrar fundamentos da violência na condição humana ou nos homens tais com realmente são e não tais como o profeta Habacuque gostaria que eles fossem, ou seja, a violência não é uma ciência normativa que dependa da religiosidade do homem, para o qual Deus teria enviado os profetas e sacerdotes, determinado uma lei escrita e definido o que poderia comer e beber, como festejar, cultuar, definindo o bem e o mal através dos mandamentos e cerimoniais civis e religiosos com o qual se construiria uma sociedade harmônica e transcendenteria a paz divina nas atividade humana, de forma que ficasse imanente na sociedade através das ações de emoções: medo, alegria, tristeza, raiva, surpresa, amor, ódio, e, ações de sentimentos que são condições específicas de obediência aos deveres civis e religiosos.

\section{Conclusão}

A percepção de que Deus é violento no Antigo Testamento se baseia na concepção da linguagem antropomórfica, isto é, dar forma humana a Deus. Entendemos que a violência e uma característica humana que tem seus viés como principio originário do poder e da justiça. Através da lente humana na interpretação bíblica aparentemente o homem pode enxergar um Deus violento, na verdade, a violência que o ser humano atribui à Deus não passa da revelação de sua própria violência. O homem enxergar um Deus que também age com violência, num certo estágio de sua crença.

Na sociedade moderna, uma justiça distorcida pode ser comparado s uma justiça tardia, ao abuso de autoridade, ao excesso de autoridade, a manipulação da justiça em função dos interesses de alguns sobre os outros. Uma justiça tardia é ineficaz por não ser justiça. Diante de uma justiça distorcida o pobre é incapaz de defender-se da violência opressora dos ricos e poderosos, então será oprimido, injustiçado, maltratado, vilimpediado, exovalhado, depauperado e merecedor de toda sorte de infortúnio. "A Justiça tem que ser, acima de tudo, uma ferramenta de Mudança Social. De apoiar quem foi vítima das

http://periodicos.est.edu.br/index.php/estudos_teologicos/article/view/13 20, acesso em 03.02.18 
armadilhas da vida, de carregar a cruz de quem padeceu diante da espada da desigualdade. O Direito não é abstrato, assim como a fome e a dor do desamparado também, absolutamente, não é.”.33

A violência que é a causa originária do poder e da justiça (direito), quando justiça é distorcida se instala o princípio hobbesiano de "todos contra todos", "o homem é o lobo do homem", cada um querendo fazer a sua própria justiça e aí que alguns apelam para justiça divina. A justiça divina invocada pelo homem sofredor, injustiçado é um gesto violento de caráter destrutivo requerendo que a "violência divina" que crie caminhos como meio de aplicar a justiça. Pois exatamente o que o profeta Habacuque fez, e é exatamente que o Estado Leviatã de Hobbes propõe. "A violência divina é o gesto que legitima a justiça, longe da mera força e da autoridade que apenas força a lei." 34

Olhando para sociedade moderno é possível identificar os mesmos questionamentos do profeta Habacuque, opressão, violência física generalizada seja por um poder paralelo, ilegal, seja pela legalidade do poder constituído manifesto pelo abuso de autoridade. A corrupção se alastra, o pobre cada vez mais oprimido e a justiça totalmente desacreditada, frouxa, distorcida. $O$ que podemos fazer? Não podemos ser complacentes com a violência cotidiana, com a institucionalizada da injustiça. Não podemos perder as esperanças de uma sociedade melhor, mais justa, mais humana. Necessitamos do endurecimento do poder estatal, leis mais severas, a justiça mais rígida e mais justas, que bem aplicadas constituíram em elementos capazes de refrear a violência e instalar uma sociedade de paz e justiça social.

\section{Referências}

33 FRANCESCO, Wagner. A justiça, a Bíblia e a opção pelos pobres. Texto disponível em: http://justificando.cartacapital.com.br/2015/06/29/a justica-a-biblia-e-a-opcao-pelos-pobres/, capiturado em 24.02.18

34 CANTINHO, João Maria. Do conceito de Violência Divina em Benjamin ao Conceito de Violência emZizek. Disponível em: https://mjcantinho.com/2014/05/01/do-conceito-de-violencia-divina-embenjamin-ao-conceito-de-violencia-em-zizek/, capturado em: 24.02.18. 
ALVES, Rubens. O que é religião". São Paulo: Brasiliense, 1984.

BELTRAMI, Fábio. Força de lei: o fundamento místico da autoridade. Conjectura: Filos. Educ., Caxias do Sul, v. 18, n. 3, p. 196-199, set./dez. 2013, p. 199

BINGEMER, Maria Clara. Violência e religião: questão prioritária. Disponível em Este www.teologiahoy.com, acesso em 03.02.18.

CANTINHO, João Maria. Do conceito de Violência Divina em Benjamin ao Conceito de Violência em Zizek. Disponível em: https://mjcantinho.com/2014/05/01/do-conceito-deviolencia-divina-em-benjamin-ao-conceito-de-violencia-emzizek/, capturado em: 24.02.18.

DERRIDA, Jacques. Força de lei. São Paulo: M. Fontes, 2010. P.19

FÉLIX, Luciene. A violência da justiça. Disponível em http://www.esdc.com.br/CSF/artigo 2009 07 Violencia da Justica.htm, capturado em 23.02.18

FILHO, Élcio Verçosa. A Providência dos Profetas: uma leitura da doutrina da ação divina na bíblia hebraica a partir de Abraham Joshua Heschel. Cadernos Teologia Prática: UNISINOS, ano XI, número 83, 2014.

FRANCESCO, Wagner. A justiça, a Bíblia e a opção pelos pobres. Texto disponível em: http://justificando.cartacapital.com.br/2015/06/29/a-justicaa-biblia-e-a-opcao-pelos-pobres/, capiturado em 24.02.18

HOBBES, Thomas. O Leviatã. São Paulo: Victor Civita Editor, 1974.

Leviatã ou matéria: forma e poder de um estado eclesiástico e civil. Tradução de João Paulo Monteiro e Maria Beatriz Nizza da Silva. $2^{\mathrm{a}}$ ed. Os pensadores. São Paulo: Abril Cultural, 1979. P. 75-76

JORDÃO, Francisco Vieira. A religião sob o ponto de vista filosófico. Revista Filosófica de Coimbra - n. ${ }^{\circ} 4$ - vol . 2 (1993 ) pp. 295-311 
KIPP, Nelson. A sociedade e a religião do Israel libertado. São Leopoldo: Est. Revista Estudo Teológicos. ISSN 0101-3130 (impresso) ISSN 2237-6461 (eletrônico). Texto disponível em http://periodicos.est.edu.br/index.php/estudos_teologicos/ar ticle/view/1320, acesso em 03.02.18.

LOCKE, John. Carta acerca da tolerância. São Paulo: Abril Cultural, pág. 03-39

MANGONI, José Antonio. Violência e idolatria no cristianismo. Porto Alegre: PUC, dissertação de mestrado, Disponível em

http://meriva.pucrs.br/dspace/bitstream/10923/5295/1/000 269461-Texto\%2BCompleto-o.pdf, capturado em 24.02.18

MATOS, Ismar Dias. Uma descrição do elemento humano em Thomas Hobbes. São Paulo: Annablume, 2007. P. 62

MATOS, Ismar Dias. Hobbes e a violência. Sapere aude - Belo Horizonte, v. 7 - n. 12, p. 509-514, Jan./Jun. 2016 - ISSN: 2177-6342. P.511

MENDES, Juscelino Vieira. O Positivismo Jurídico de Hans Kelsen e o profeta-filósofo Habacuque: determinantes na aplicação da Justiça. Revista de direito: Kroton Educacional, v. 9, n. 11, 2006

OLIVEIRA, Irene Dias, apud. Religião, violência e suas interfaces. São Paulo: Paulinas, 2012.

RODRIGUES, Elisa. As Ciências Sociais da Religião como Ciências da Interpretação. Estudos de Religião, v. 28, n. 1, 186-203, jan.-jun. 2014

SANTOS, Rodrigo Ponce. Hobbes e a filosofia do poder: os 'princípios' antipolíticos do leviatã na leitura de Hannah Arendt. KRITERION, Belo Horizonte, $n^{o}$ 136, Abr./2017, p.211

SANTOS, Tiago Bueno. A estruturação da religião monoteísta no antigo Israel. UNITAU: XIV Encontro Latino Americano de Iniciação Científica e X Encontro Latino Americano de PósGraduação - Universidade do Vale do Paraíba. Disponível em http://www.inicepg.univap.br/cd/INIC 2011/anais/arquivos/ 0266 0173 04.pdf, acesso em 14.02.18.p.1 
SAYÃO. Luiz. O problema do mal no Antigo Testamento: o caso de Habacuque. São Paulo: Hagnos. 2012

VANIER, Alain. Direito e violência. Ágora v. VII n. 1 jan/jun 2004 129-141. 